Supporting Information

\title{
High Resolution Atmospheric Modeling of Fluorotelomer Alcohols and Perfluorocarboxylic Acids in the North American Troposphere
}

Greg Yarwood $^{1 *}$, Susan Kemball-Cook ${ }^{1}$, Michael Keinath ${ }^{2}$, Robert L. Waterland ${ }^{3}$, Stephen H. Korzeniowski ${ }^{3}$, Robert C. Buck ${ }^{3}$, Mark H. Russell ${ }^{3}$, and Stephen T. Washburn ${ }^{2}$

${ }^{1}$ ENVIRON International Corporation, Golden Gate Plaza, 101 Rowland Way, Novato, CA 94945

${ }^{2}$ ENVIRON International Corporation, 6001 Shellmound St., Suite 700, Emeryville, CA 94608

${ }^{3}$ E. I. du Pont de Nemours and Company, Wilmington, DE 19805

*Corresponding Author E-mail: robert.l.waterland@usa.dupont.com

\section{$\underline{\text { Table of Contents }}$}

$\underline{\text { Page }}$

CAMx Model

2

The role of NOx chemistry and model resolution in the simulation of FTOH degradation

Simulation of FTOH degradation outside the CAMx domain

Emissions Inventory Methodology

Emissions estimates

Emissions calculations

Methodology used to calculate DuPont fluorotelomer emissions in NA

Figure S1: Geographic regions for emission apportionment

Table S1: Estimated annual air emissions of PFCAs and FTOHs ...

Table S2: Comparison of model characteristics of IMPACT and CAMx

Table S3: Comparison of modeled and monitored atm conc of 8:2 FTOH

Table S4: Comparison of modeling results for atm conc of PFOA

Methodology used to calculate PFCA deposition from Scott et al

Detailed chemical mechanism

Table S5: Chem mechanism for OH-radical initiated chem degn of 8:2OH

Figure S2: Mechanism for gas-phase chem degn of 8:2 FTOH

Figure S3: Ann ave ground-level air conc of 8:2 FTOH in NA

Figure S4: Fractional yields of PFOA and PFNA from 8:2 FTOH
2 


\section{$\underline{\text { CAMx Model }}$}

The current version (version 4.20) of the CAMx model, as publicly released at www.camx.com, was used with the addition of the chemical mechanism for FTOH degradation described below. CAMx is a three-dimensional photochemical grid model meaning that it represents the atmosphere as a three-dimensional array of boxes. For this analysis, each grid box is $72-\mathrm{km}$ square with a depth that varies according to the model layer. The model's vertical resolution is finest near the ground (36 meter surface layer) and extends to the lower stratosphere in 20 layers. Meteorological data for CAMx were developed using the PSU/NCAR Mesoscale Model version 5 (MM5) for calendar year 2002. The MM5 provides CAMx with hourly, gridded data for wind vectors, pressure, temperature, diffusivity, humidity, clouds and rainfall. Emissions of volatile organic compounds (VOCs), nitrogen oxides (NOx), $\mathrm{CO}, \mathrm{SO}_{2}, \mathrm{NH}_{3}$ and aerosols were from the Environmental Protection Agency's 2002 National Emissions Inventory. The CAMx modeling databases were originally developed for current regulatory modeling of visibility and particulate matter in the U.S. Each year-long CAMx simulation was completed in one week using two LINUX personal computers with dual core AMD Athlon processors (1990 MHz). Input data for the CAMx simulations required approximately 50 gigabytes of disk space.

The Role of NOx Chemistry and Model Resolution in the Simulation of FTOH Degradation

$\mathrm{NO}_{\mathrm{x}}$ plays a key role in determining the extent to which PFCAs form as FTOHs degrade. The from tropospheric ozone chemistry is that ozone formation switches between sensitivity to volatile organic compound (VOC) or NOx precursors depending upon the $\mathrm{VOC} / \mathrm{NO}_{\mathrm{x}}$ ratio (see textbooks by Seinfeld and Pandis ${ }^{4}$ or Warneck ${ }^{17}$ ). Transitions from VOC to NOx sensitivity occur at fine spatial scales (a few kilometers) and temporal scales (hour-to-hour) such that ozone models must have fine spatial resolution (less than $\sim 36 \mathrm{~km}$ grid) to accurately model ozone chemistry. Similarly, the air modeling for this assessment should be capable of fine spatial will run a gauntlet of high- and low-NOx regions as they traverse the model domain. Their residence time in regions of high or low NOx will determine the likelihood that the FTOH reaction products will proceed down the chemical pathway to PFCA formation. A model with high spatial resolution is well-suited to describe this process, while a lower resolution model will tend to smooth out the ambient NOx distribution, reducing average NOx concentrations. This biases lower-resolution models toward higher PFCA yields, as the FTOH molecule and its products spend more time in a low-NOx environment.

\section{Simulation of FTOH Degradation Outside the CAMx Domain}

With the inclusion of recirculation, up to $99 \%$ of the emitted 8:2 FTOH degrades within one circuit of the northern hemisphere. After 30 days of chemical processing and rain events, recirculated species are reintroduced to CAMx uniformly along the northern and western boundaries of the domain, according to global circulation patterns.

\section{Emissions Inventory Methodology}

DuPont's fluorotelomer-based products were divided into five product categories. For each product class, releases were estimated at each stage of a fluorotelomer-based product's lifecycle 
(manufacture, industrial application, consumer use and disposal) based on expected usage of that class of products. For geographical apportionment, manufacturing releases were assumed be released at DuPont fluorotelomer manufacturing facilities. Releases during industrial application were split among thirteen geographical regions in North America based on DuPont sales data. Within each geographical region, the aggregated release estimates were distributed according to population density. Release estimates for consumer use and disposal were distributed according to population density throughout Canada, the United States and Mexico).

Based on the raw ingredients and process chemistry used for manufacturing, the fraction of fluorinated active ingredient and a representative molecular weight profile was determined for each product. The resulting product molecular weight profiles include the following range of fluorocarbon chain lengths: C4, C6, C8, C10, C12, C14 and higher.

\section{$\underline{\text { Emissions estimates }}$}

For each portion of the emissions cycle, separate emissions to air, land and water were estimated. Values for manufacturing emissions were based on data obtained from DuPont manufacturing locations (which are all located in Region 6) while customer, consumer and disposal emissions were based on best estimates obtained from compiling global mass balances of fluorotelomers (see related paper on fluorotelomer sources by Cousins et al., 2006, EST 40(1):32-44).

Two sets of emissions values were developed. Current environmental releases for 2004 to air, land and water represent the historical release patterns for fluorotelomers and their residuals based on documented and estimated release patterns. Future releases, for the years 2007 and beyond, reflect the planned reductions in manufacturing releases as well as reductions in the residual content of products used by customers and consumers.

Total North American emissions from manufacture, use and disposal of fluorotelomer-based products from all sources were estimated by assuming that DuPont emissions represented $40 \%$ of total North American emissions. As a result, the predicted atmospheric concentrations of FTOHs and PFCAs were multiplied by a factor of 2.5 to permit comparison of the model predictions with available monitoring data. This correction factor was not applied in the immediate vicinity of major manufacturing locations since these local emissions are typically dominated by the local source.

Total global emissions from manufacture, use and disposal of fluorotelomer-based products from all sources were estimated by assuming that total North American emissions represented one third of global emissions. As a result, the predicted atmospheric concentrations of FTOHs and PFCAs were multiplied by a factor of $2.5 \times 3=7.5$ to permit comparison of the model predictions with the IMPACT model results. 


\section{$\underline{\text { Emissions calculations }}$}

Summaries of DuPont product sales, including sales volume, fractional fluorinated active ingredient, molecular weight distribution and residual content were prepared for 2004 and 2007. Summaries were prepared by region as well as for all of North America; the summaries for all of North America contained information on product cycle, environmental media, product class and chain length.

The emissions values for each region represent the combined releases from manufacturing, customer use, consumer use and disposal for all products sold and used within each region.

Products sold to customers in a specific region are assumed to be disposed of in that same region. The geographic distribution of these products within a region is assumed to be proportional to the distribution of local population, with use and disposal determined on a per capita basis.

A summary of the estimated annual air emissions of PFCAs and FTOHs associated with the production, use, and disposal of DuPont's fluorotelomer-based products in North American for 2004 and 2007 are provided in Table S1.

\section{Methodology used to calculate DuPont fluorotelomer emissions in North America}

Annual global sales data for the fluorotelomer-based products of DuPont Chemical Solutions Enterprise (DCSE) are stored in a database maintained by the company. This database was queried to obtain all product sales of fluorotelomer-based products (intermediates, polymers and surfactants) for the USA, Mexico and Canada for the years 1999 through 2005 (year-to-date). North American sales data listing the product name, composition, pounds sold and the customer's name and address were compiled and sales data for the year 2004 were selected, as 2004 was the most recently completed year. Regional sales were compiled for thirteen geographic regions distributed across North America:

Region 1: Northwestern USA (ID, OR, WA)

Region 2: Southwestern USA (AZ, CA, NV, UT)

Region 3: North Central USA (ND, NE, MT, SD, WY)

Region 4: South Central USA (CO, KS, NM, TX, OK, AR, LA, MS, TN, AL)

Region 5: Midwestern USA

Region 6: Northeastern USA

Region 7: Southeastern USA

Region 8: Mexico

Region 9: British Columbia, Canada

Region 10: Central Canada (Alberta, Saskatchewan, Manitoba)

Region 11: Ontario, Canada

Region 12: Eastern Canada (Quebec, Newfoundland, Labrador, New Brunswick, Prince Edward)

Region 13: Northern Canada (Yukon, Northwest Territories, Nunavut) and Alaska 


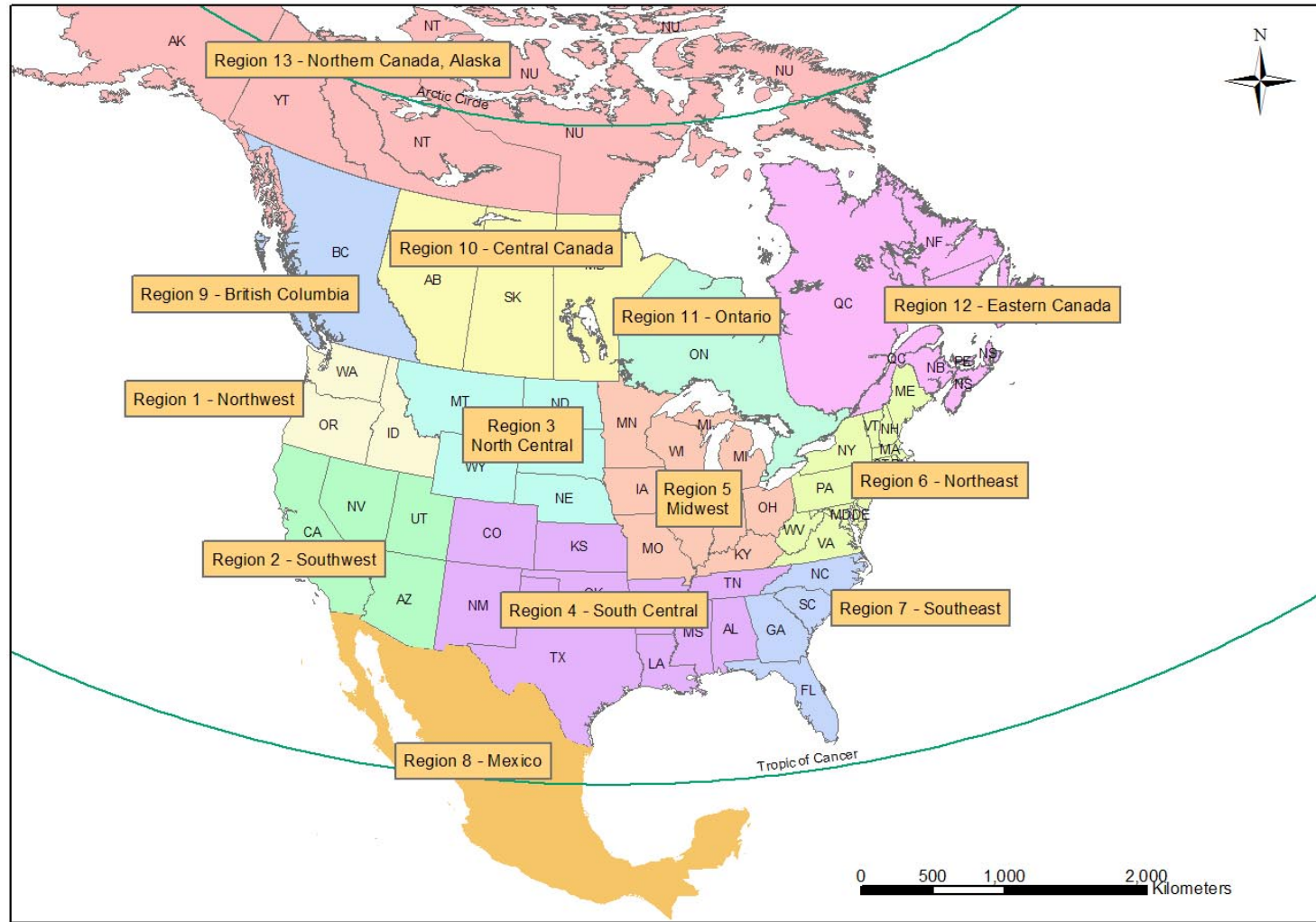

Figure S1: Geographical Regions for Emission Apportionment 
Table S1: Estimated annual air emissions of PFCAs and FTOHs associated with the production, use, and disposal of DuPont's fluorotelomer-based products in North America

\begin{tabular}{ccc}
\hline Compound & $\begin{array}{c}\text { Baseline (2004) Scenario } \\
{[\mathbf{k g} / \mathbf{y r}]}\end{array}$ & $\begin{array}{c}\text { Future (2007) Scenario } \\
{[\mathbf{k g} / \mathbf{y r}]}\end{array}$ \\
\hline 8:2 FTOH & 20,237 & 574 \\
10:2 FTOH & 10,435 & 305 \\
12:2 FTOH & 3,813 & 130 \\
14:2 FTOH & 2,032 & 91 \\
PFOA & 101 & 5 \\
PFDA & 55 & 3 \\
\hline
\end{tabular}


Table S2. Comparison of Model Characteristics of IMPACT and CAMx

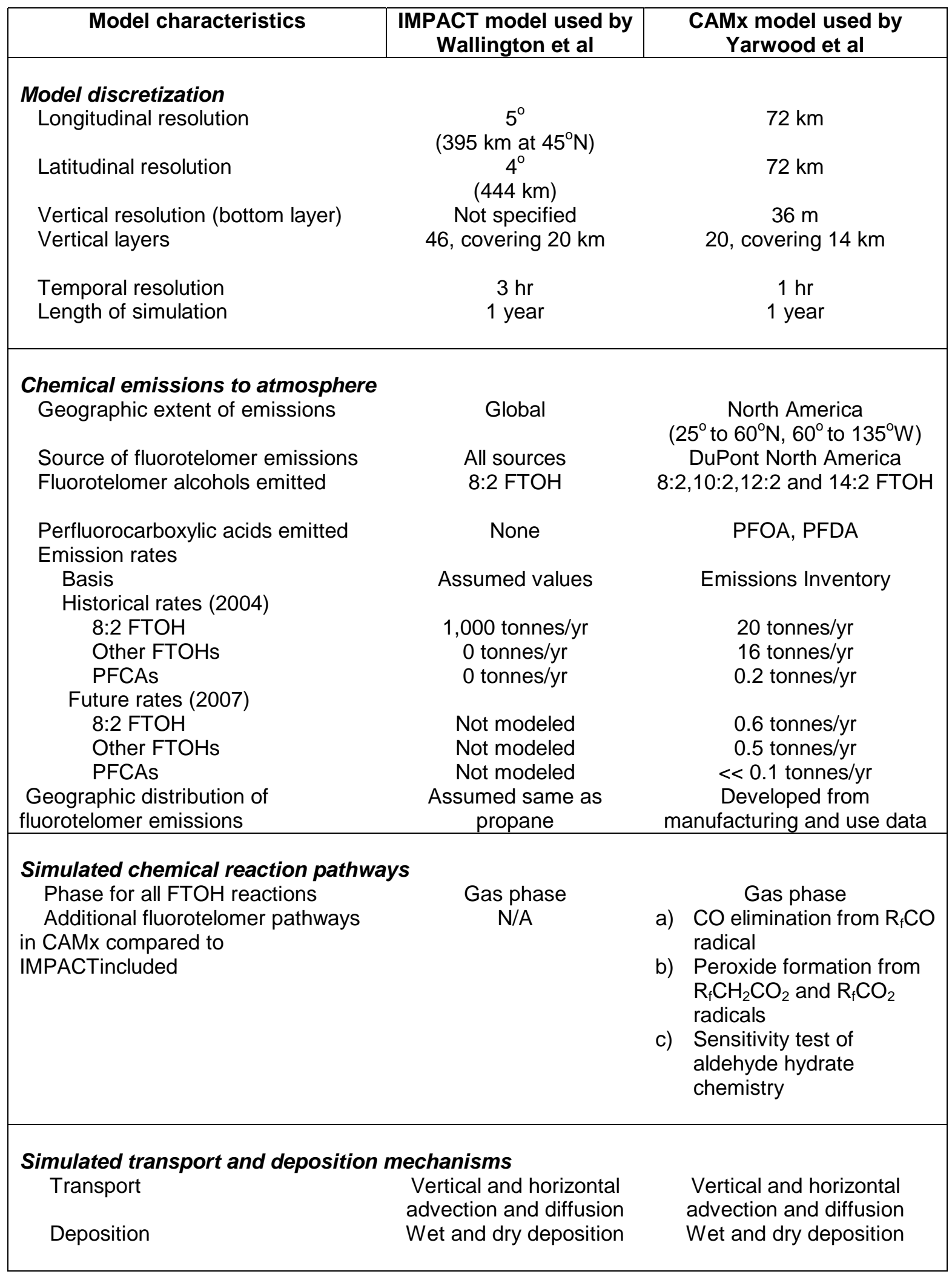


Table S3. Comparison of modeled and monitored atmospheric concentrations of 8:2 FTOH

\begin{tabular}{cccc}
\hline Location & $\begin{array}{c}\text { CAMx (1) } \\
(\mathrm{pg} / \mathrm{m} 3)\end{array}$ & $\begin{array}{c}\text { Monitoring (2) } \\
(\mathrm{pg} / \mathrm{m} 3)\end{array}$ & $\begin{array}{c}\text { Monitoring (3) } \\
(\mathrm{pg} / \mathrm{m3})\end{array}$ \\
\hline Georgia & 755 & 130 & -- \\
Manitoba & 15 & 10 & -- \\
Nevada & 25 & 40 & -- \\
Ohio & 30 & 65 & -- \\
Ontario 1 & 48 & 1 & -- \\
Ontario 2 & 35 & 80 & 40 \\
Ontario 3 & 50 & -- & \\
\hline
\end{tabular}

Notes: (1) CAMx results have been scaled by a factor of $2.5 \mathrm{X}$ to account for total industry emissions in North America

(2) Data of Stock et al. , Env Sci \& Tech 2006, 38 (4) 991-996.

(3) Data of Shoeib et al. , Env Sci \& Tech 2006, 40 (24) 7577-7583. 
Table S4. Comparison of modeling results for atmospheric concentrations of PFOA

\begin{tabular}{|c|c|c|c|c|}
\hline \multirow{2}{*}{\multicolumn{2}{|c|}{$\begin{array}{c}\text { Source of concentration } \\
\text { vales }\end{array}$}} & \multicolumn{3}{|c|}{ Predicted or measured atmospheric concentrations of PFOA $(\mathrm{pg} / \mathrm{m} 3$} \\
\hline & & \begin{tabular}{|c|} 
Regional: \\
In regions adjacent to \\
point sources
\end{tabular} & $\begin{array}{c}\text { Continental: } \\
\text { In remainder of } \\
\text { continental USA }\end{array}$ & $\begin{array}{c}\text { Remote: } \\
\text { In Canadian Arctic }\end{array}$ \\
\hline \multirow{2}{*}{ Modeling } & CAMx & $0.04-0.36$ & $0.01-0.09$ & $<0.001-0.003$ \\
\hline & IMPACT & $0.03-0.08$ & $0.03-0.08$ & $0.01-0.15$ \\
\hline
\end{tabular}

Concentration values from CAMx have been scaled as follows:

regional: no scaling, concentrations are assumed to be dominated by local emission sources continental: increased to $50 \mathrm{t} / \mathrm{yr}(2.5 \mathrm{X})$ to account for total North American fluorotelomer production remote: increased to $150 \mathrm{t} / \mathrm{yr}(7.5 \mathrm{X})$ to account for total global fluorotelomer production

Concentration values from IMPACT have been scaled as follows:

all values: decreased to $150 \mathrm{t} / \mathrm{yr}(0.15 \mathrm{X})$ to account for total global fluorotelomer production 


\section{Methodology used to calculate PFCA deposition from data of Scott et al. 2006}

In Table 3 of the Scott et al. (Environ. Sci. Technol. 2006 41(23), 7167-7174) monitoring study, average PFCA fluxes in precipitation are reported for a series of locations across North America. The mean flux of PFOA and PFNA for each location were multiplied by the number of samples to obtain a cumulative yearly deposition for each PFCA. The results of these calculations are provided in Table 5 of this paper.

\section{Detailed Chemical Mechanism}

Species names follow the naming convention for $8: 2 \mathrm{FTOH}$, or $82 \mathrm{OH}$, where " 8 " is the number of fluorinated carbon atoms and "2" is the number of non-fluorinated (generally hydrogenated or oxygenated) carbon atoms. Thus, PFOA is denoted as 71CA and perfluorononanoic acid (PFNA, $\mathrm{CF}_{3}\left(\mathrm{CF}_{2}\right)_{7} \mathrm{COOH}$ ) is denoted 81CA. The mechanism follows the scheme outlined by Ellis et al. (Environ. Sci. Technol. 2004 38(12), 3316-3321), with some significant differences. For example, $\mathrm{CO}$ elimination from perfluoroacyl radicals is included.

The top portion of the chemical mechanism describes the degradation of the hydrocarbon portion of 8:2 FTOH by OH radical and photolysis reactions. PFNA can be formed by reaction of a perfluorinated peroxyacyl radical (81RO3) with an $\mathrm{HO}_{2}$ radical. PFOA can be formed via reaction of a perfluorinated peroxy radical (80RO2) with an $\mathrm{RO}_{2}$ radical (e.g., $\mathrm{CH}_{3} \mathrm{O}_{2}$ ). The peroxy radical reactions leading to PFNA and PFOA formation from 8:2 FTOH both have analogues in atmospheric hydrocarbon chemistry and they compete against reactions with $\mathrm{NO}$ that do not form PFCA. Consequently, the yields of PFCA from FTOH degradation will depend upon the relative abundances of peroxy radicals and NO in the atmosphere. Degradation of the perfluorinated backbone of 8:2 FTOH proceeds by an "unzipping" sequence of radical reactions producing $\mathrm{CF}_{2} \mathrm{O}$ and potentially smaller PFCAs (61CA, 51CA, etc.) by reactions analogous to those that form PFOA (71CA).

In addition to the 8:2 FTOH considered in the chemical mechanism and modeled using CAMx, there are longer-chain FTOHs associated with DuPont fluorotelomer-based products that are capable of forming PFCAs (i.e., 10:2, 12:2 and 14:2 FTOH). These compounds were considered in the analysis by analogy to the shorter chain $8: 2 \mathrm{FTOH}$. For example, the proposed chemical mechanism predicts conversion of the 8:2 FTOH to form PFCAs shorter than PFOA and PFNA (e.g., 61CA, 51CA, etc.). The 10:2 FTOH was assumed to form the 71CA (PFOA) with the same yields as the 8:2 FTOH formed the 51CA, and this yield was applied to the total release of the 10:2 FTOH to determine the contribution of the 71CA (PFOA) from the 10:2 FTOH. This process was repeated for all FTOH/PFCA combinations. 


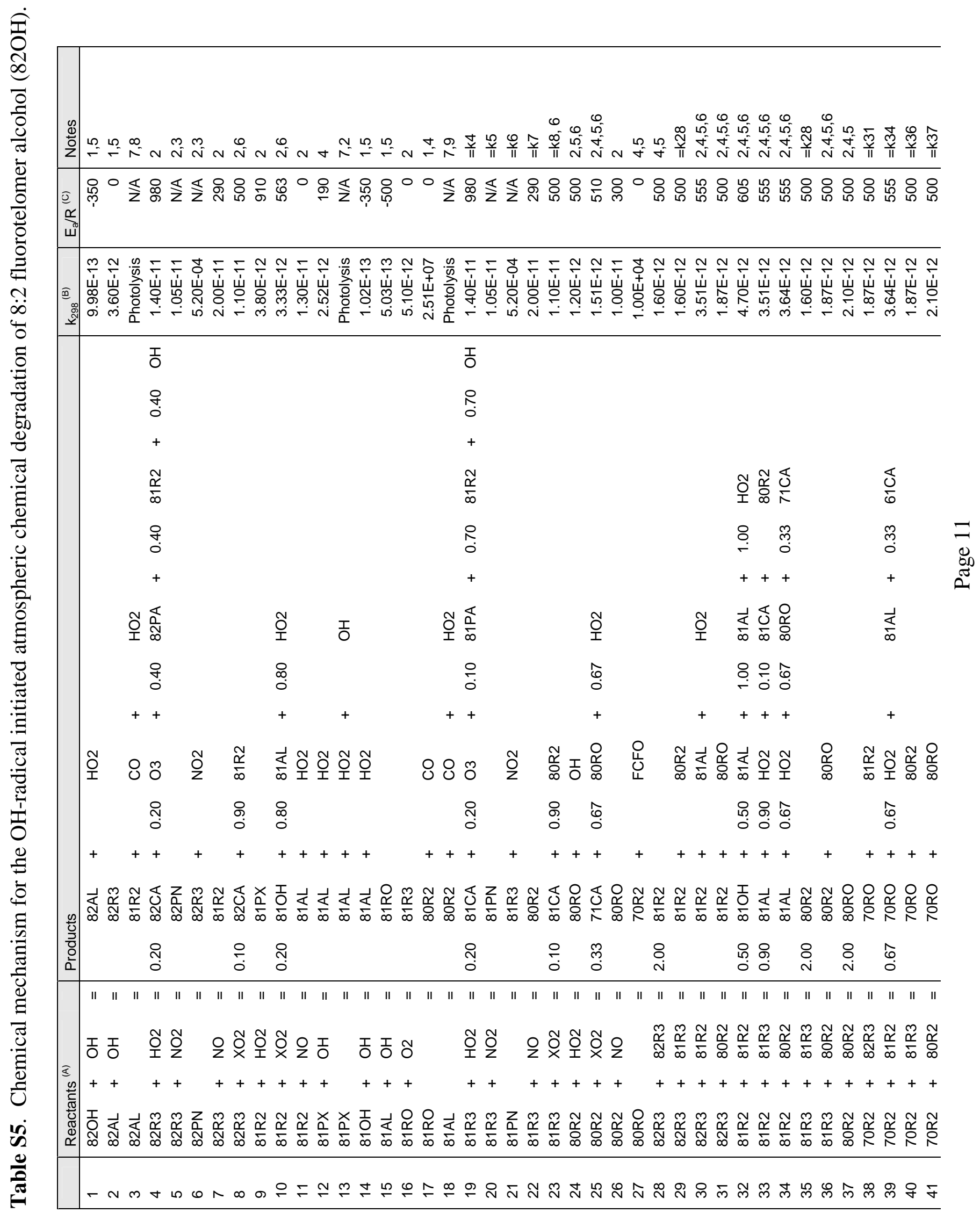




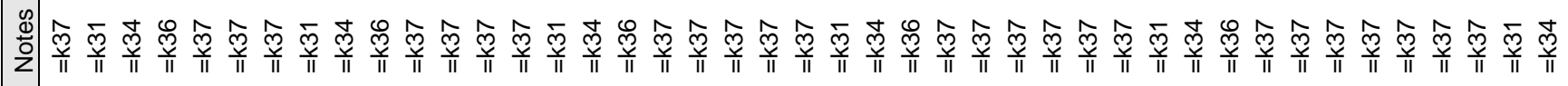

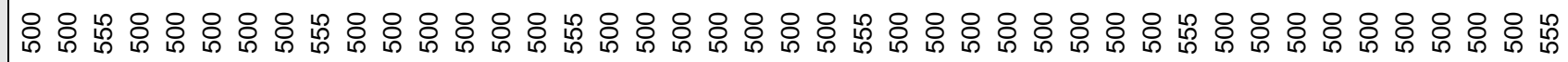

$\stackrel{\mathfrak{m}}{\mathfrak{g}}$

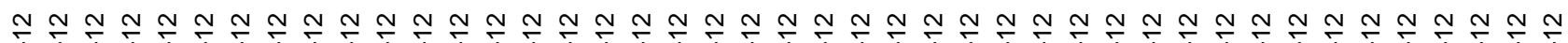
ఐ 㠃

\begin{tabular}{|c|c|c|c|c|c|}
\hline 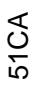 & $\begin{array}{l}\overleftarrow{J} \\
\sigma \\
\sigma\end{array}$ & $\frac{\delta}{m}$ & $\underset{N}{\mathbb{N}}$ & $\underset{O}{\stackrel{\sigma}{0}}$ & $\begin{array}{l}\overleftarrow{O} \\
0\end{array}$ \\
\hline ల్ల్ & 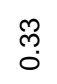 & m్ర & $\underset{0}{\mathscr{O}}$ & $\stackrel{m}{0}$ & $\stackrel{\text { ల్ }}{0}$ \\
\hline+ & + & + & + & + & 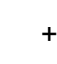 \\
\hline$\frac{1}{\infty}$ & $\underset{\infty}{\frac{1}{x}}$ & $\underset{\infty}{\overleftrightarrow{\leftarrow}}$ & $\underset{\infty}{\vec{\varangle}}$ & 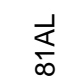 & $\underset{\infty}{\frac{1}{4}}$ \\
\hline
\end{tabular}

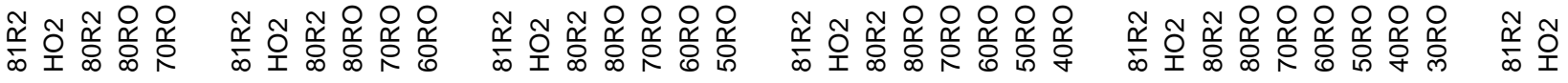

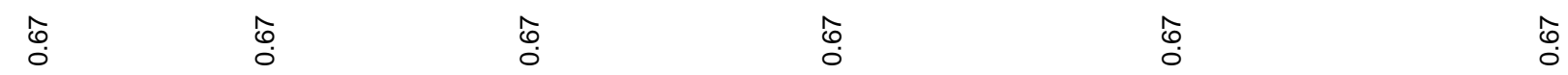

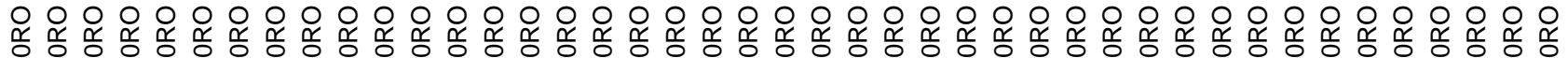

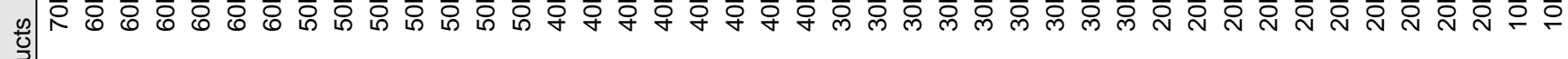

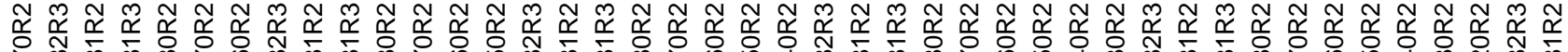
ฐ

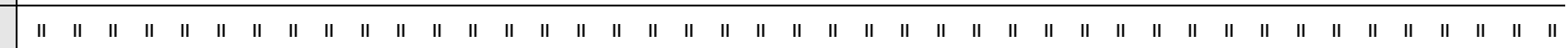

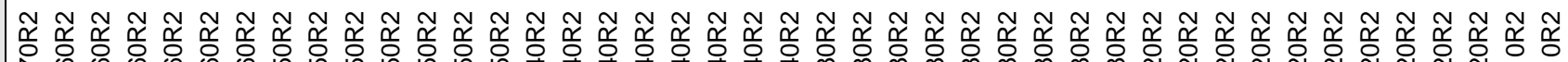

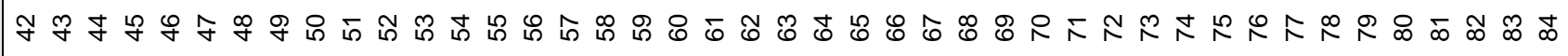




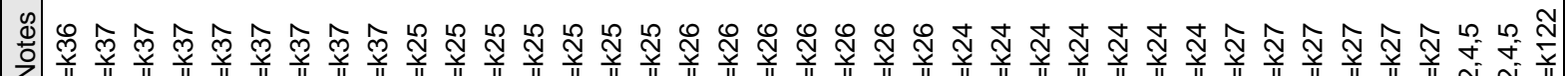

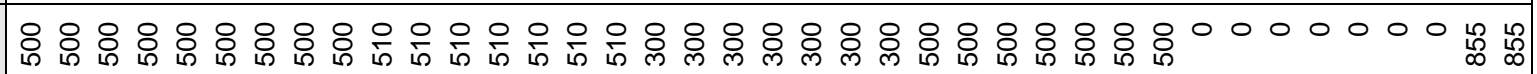
$\stackrel{\dddot{2}}{\dddot{2}}$

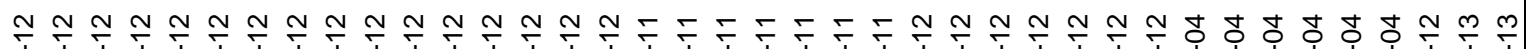
凤

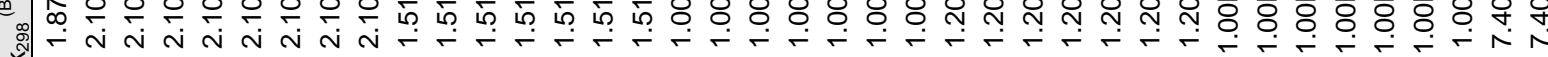

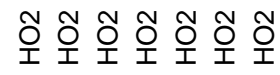

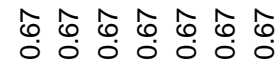

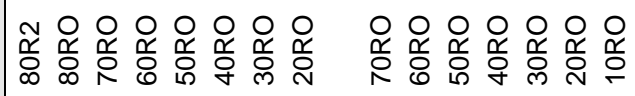

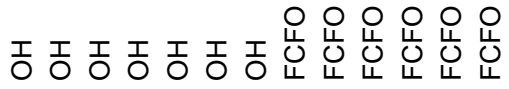

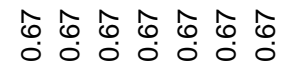

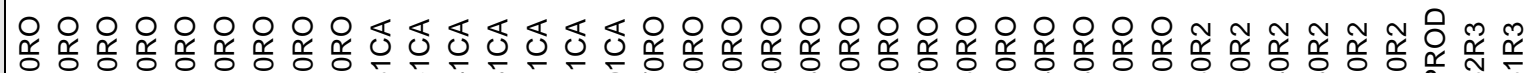

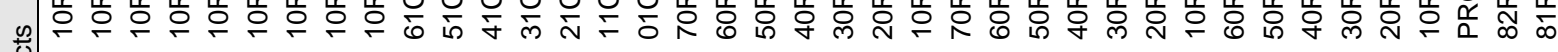

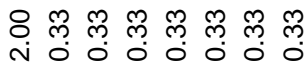

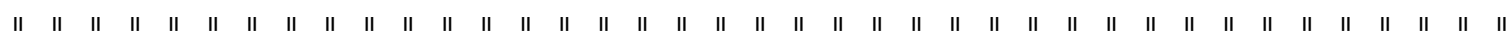

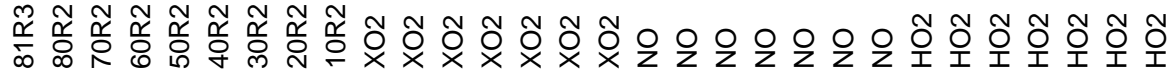

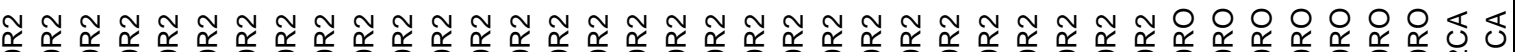

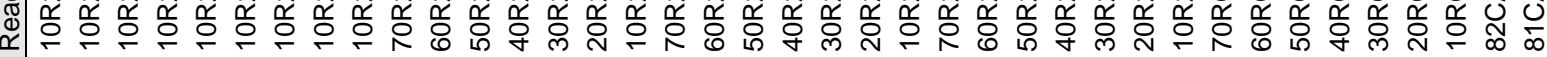

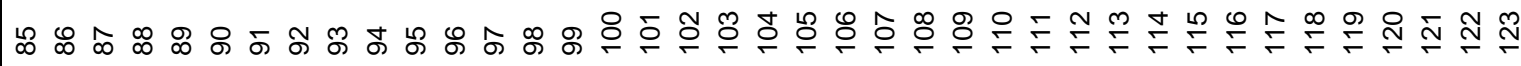




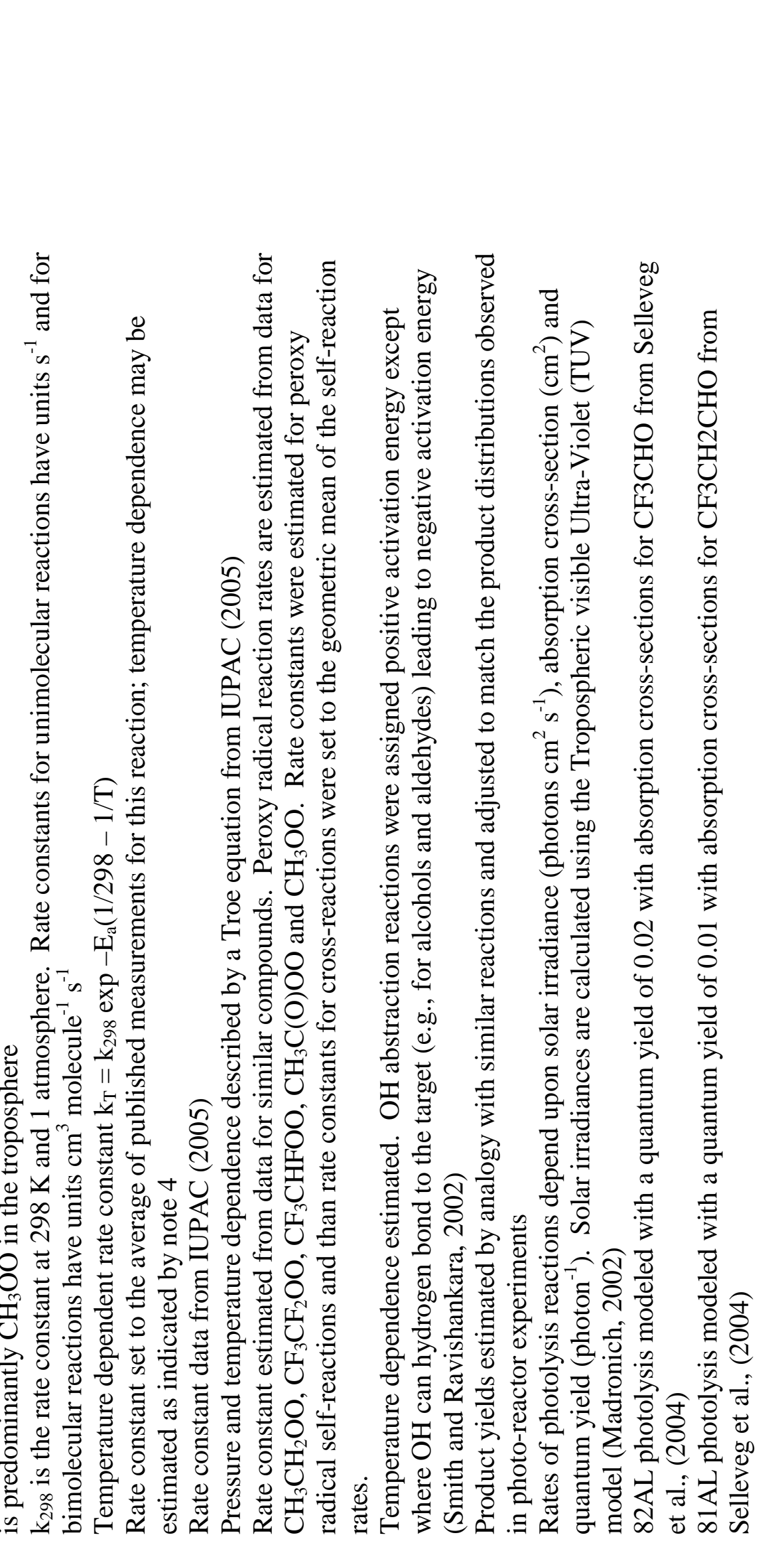

a 

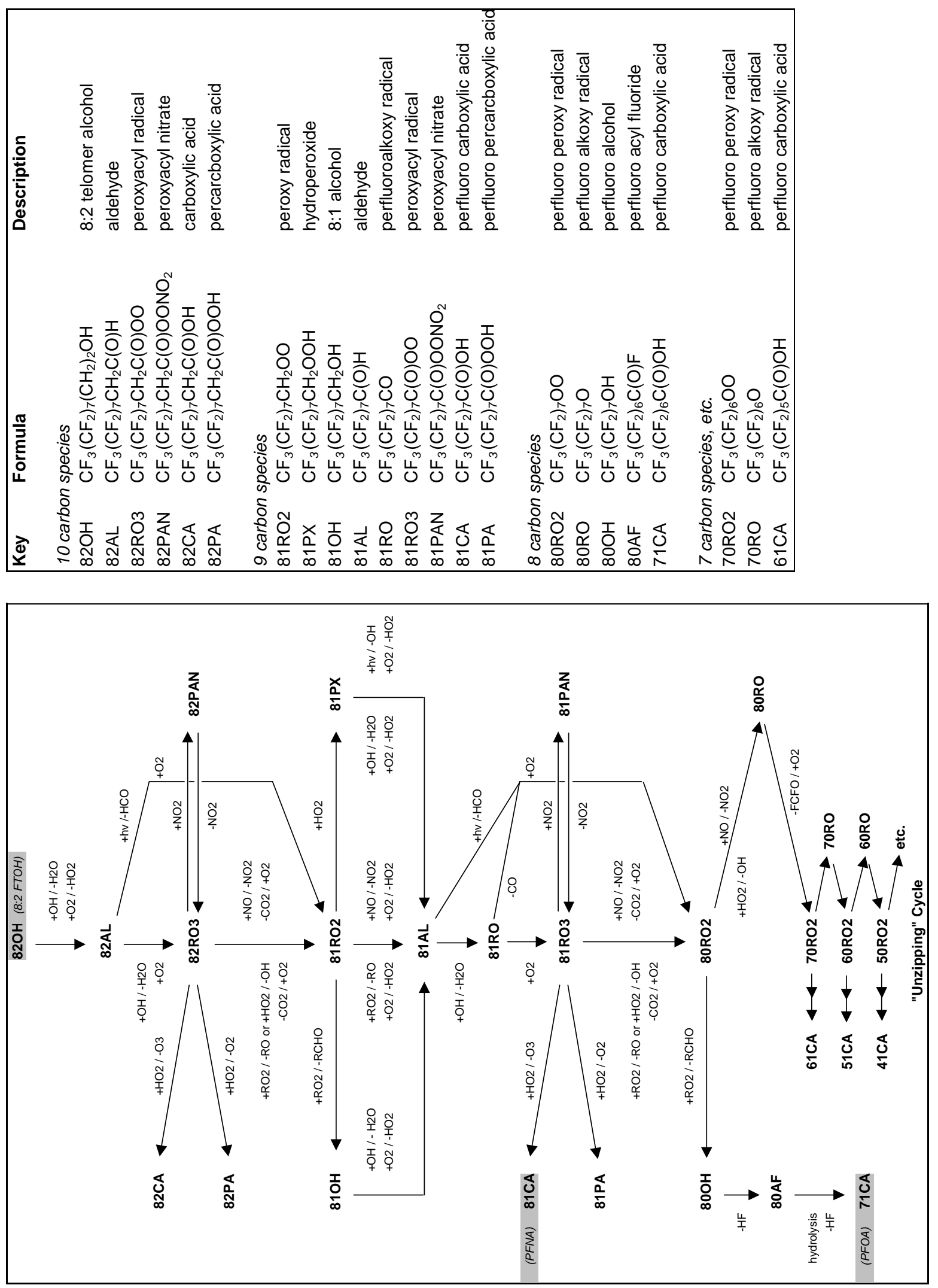

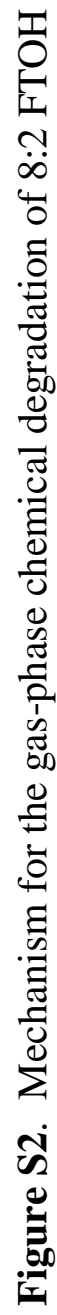


a)

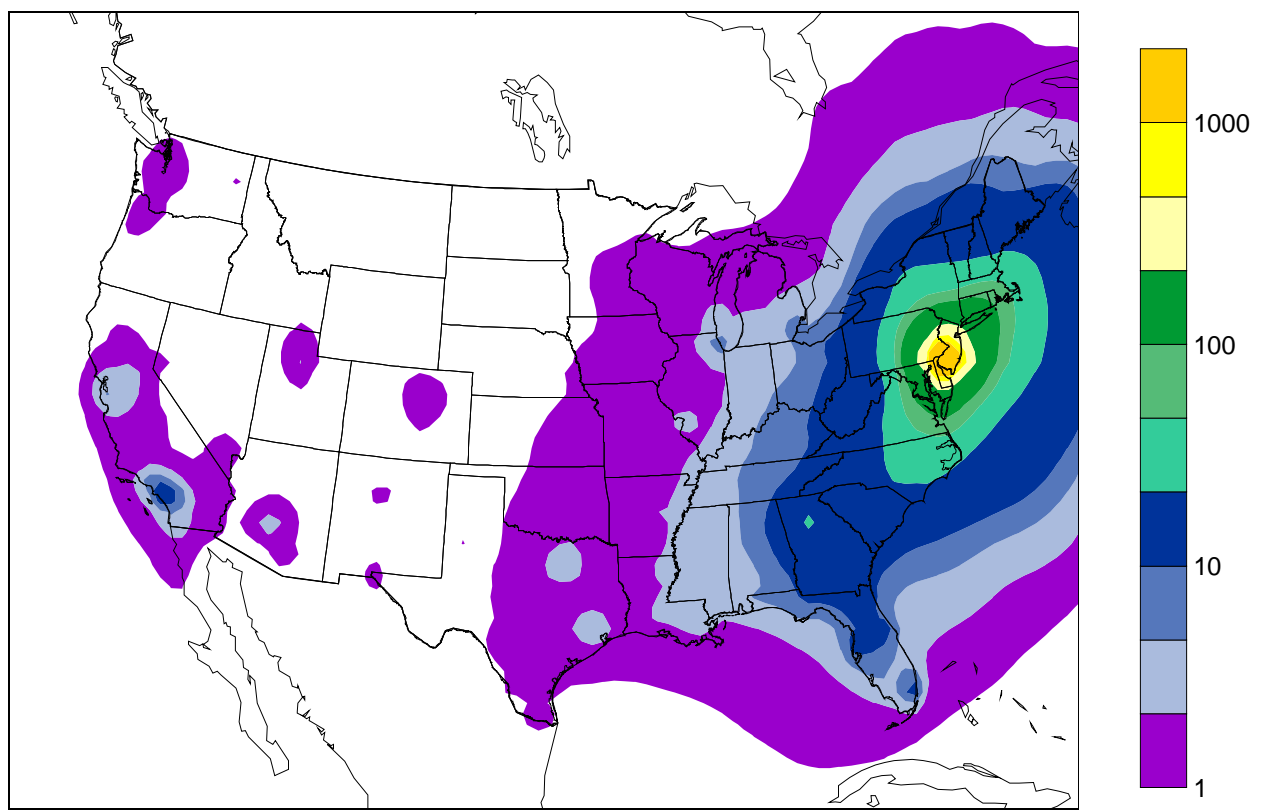

b)

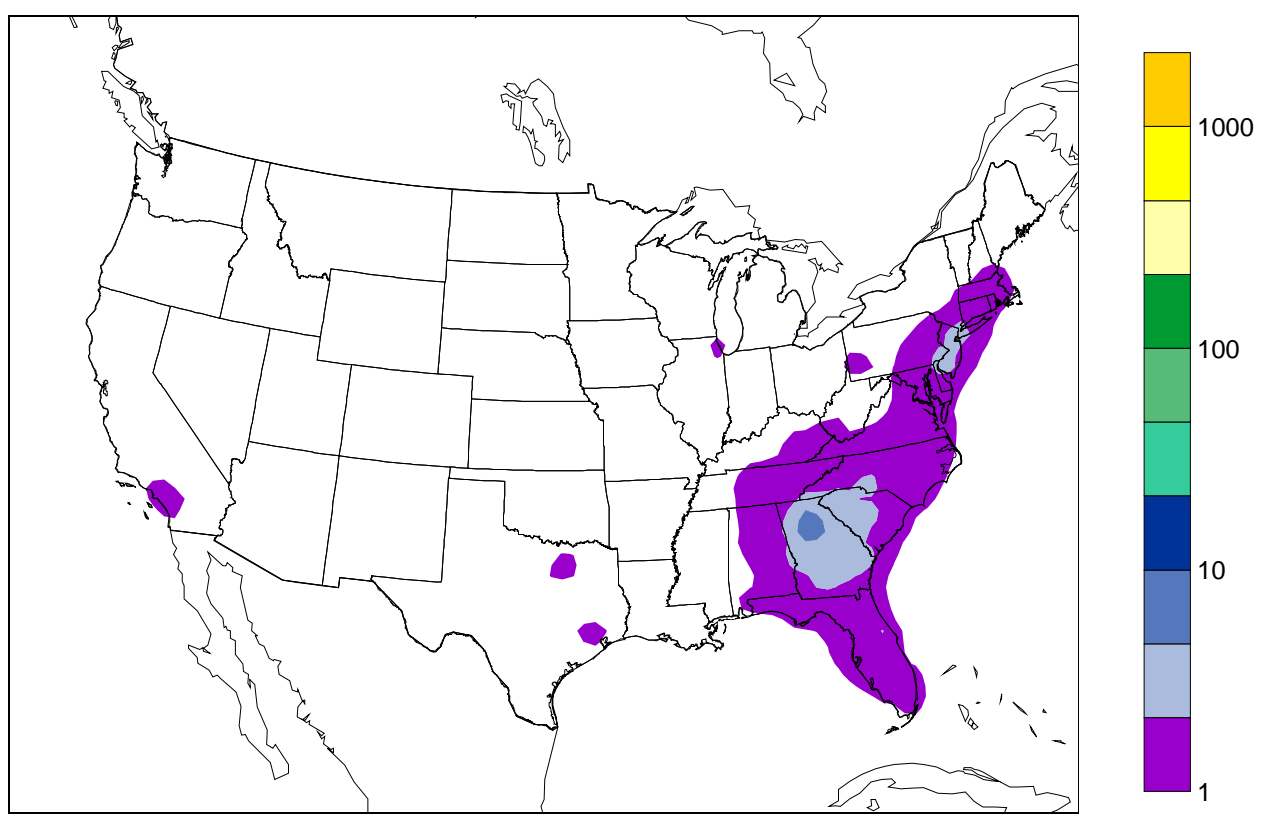

Figure S3: Annual average ground-level air concentrations $\left(\mathrm{pg} \mathrm{m}^{-3}\right)$ of 8:2 FTOH from North American ai emissions associated with the manufacture, use and disposal of DuPont fluorotelomer-based products.

a) 8:2 FTOH with baseline (2004) release estimates

b) $8: 2 \mathrm{FTOH}$ with future (2007) release estimates

The concentration ranges shown in these figures extend down to the concentration typically reported as the LOQ for detection of 8:2 FTOH in air $\left(\sim 1-2 \mathrm{pg} / \mathrm{m}^{3}\right)$. 


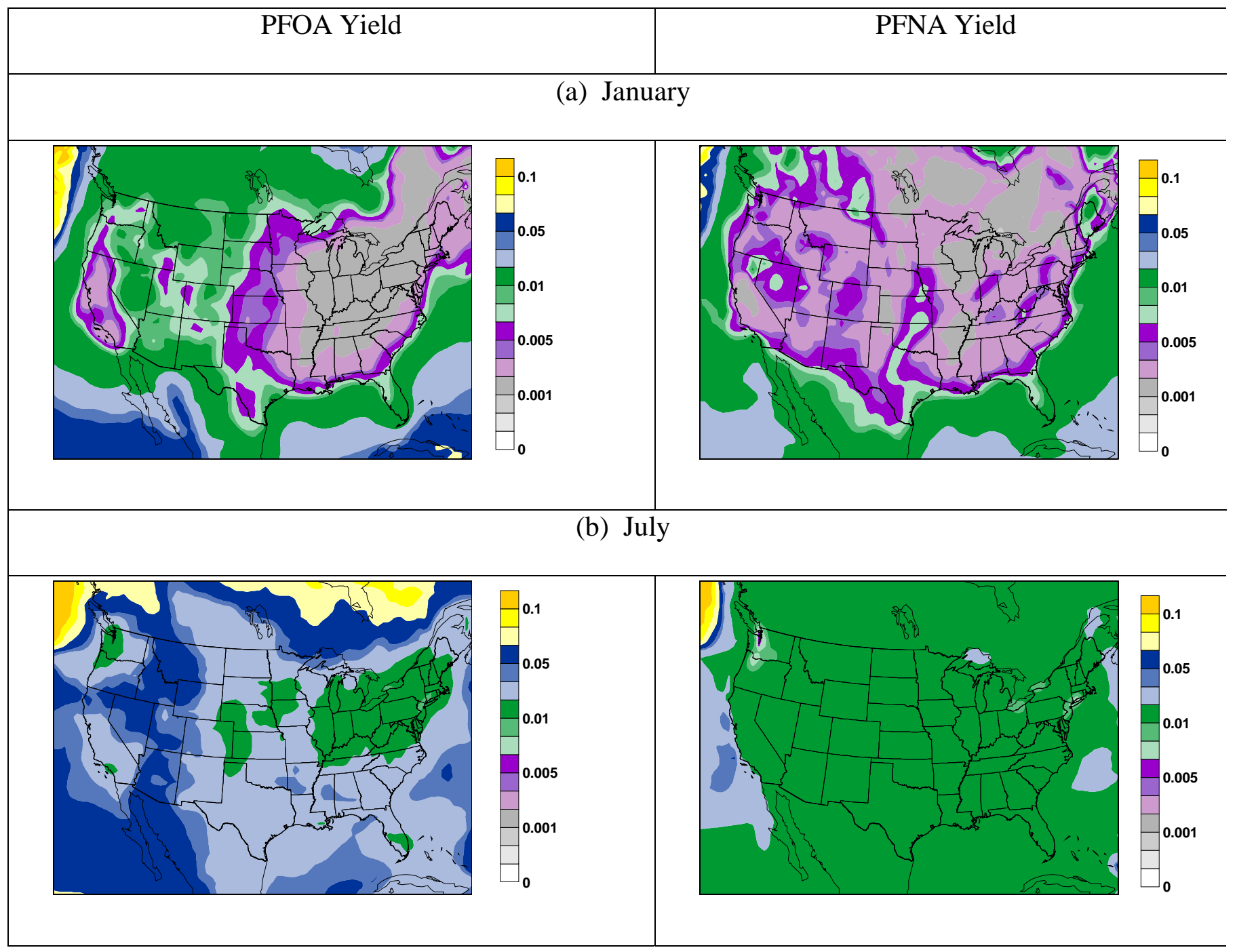

Figure S4. Fractional yields of PFOA and PFNA from 8:2 FTOH in (a) February and (b) July of 2004. 